\title{
The Russian Foundation for Basic Research: Concern for the Future of the Largest Grant Fund.
}

\author{
I.A. Sterligov, STRF.ru, exclusively for Acta Naturae
}

The Russian Foundation for Basic Research is the oldest and most highly regarded source of scientific grants in Russia. It was created by a presidential decree of Boris Yeltsin "On Urgent Measures for Conserving the Scientific and Technical Potential of the Russian Federation" in 1992. Among other lines of research, the foundation is an active supporter of life sciences, which receive approximately $20 \%$ of the available funds.

\begin{abstract}
AIMS, SCALE, AND MECHANISMS
In these times, when innovations are being implemented constantly, the Russian Foundation for Basic Research (RFBR), which is run by the government, is still an organization which first and foremost supports basic research. There is a very substantial reason for this. According to the head of the foundation's Biological and Medical Project Management Division, Valery Smirnov, "Science should not be divided into important and unimportant categories. We should always keep in mind that the foundations of modern genetics and molecular biology were all set during the course of experiments on wrinkled peas by Mendel and studies of the eye color of fruit flies."

This is why the RFBR supports projects which are not so much aimed at implementing practice (however, there is an "implementation-oriented" section, which will be mentioned later), but instead aimed at understanding and clarifying the laws and forms of nature.

Those researchers that are adept at solving such issues are offered a variety of competitions, the main one being a competition between initiative projects. Applications for conducting scientific research by individual scien-
\end{abstract}

tists or groups of less than ten people, irrespective of titles, degrees, age, etc. are accepted. The only requirement is that the applicant must work in an organization in Russia whose charter stipulates that the organization conducts scientific research.

The funding is fairly moderate; for instance, in 2009, the average grant in biology and medicine was $380000 \mathrm{ru}-$ bles. The maximal grant was 750000 rubles. "The funds we allocate to the researcher depend on the expenses required for his project," explains Smirnov. The foundation's staff acknowledges that the funding is not on par with international standards. An average grant should be approximately 1 million rubles; however, the foundation cannot accomplish this because of its own insufficient funding.

In 2010 the overall funding for biological and medical projects will be only 612 million rubles. This sum will be evenly spread between three sections: general biology, physico-chemical biology, and basic medicine and physiology. According to the directives from the board of the foundation, $30 \%$ of all the received applications must be granted. The results of the expert assessment will be published in March.

The expert assessment itself involves the following procedures. The biology and medicine department appoints an expert committee consisting of 64 people, 21-22 people for each of the three sections. This committee consists of leading Russian specialists, usually doctors of science. Directors and deputy directors of scientific organizations, state academies' staff members, etc., cannot be members of this committee. Each section consists of $8-10$ theme divisions. One or two members of the committee are experts in each of these themes.

The expert committee is approved by the foundation's council, which is, in turn, appointed by the government. The members of the expert committee can serve a maximum of two 3-year terms. These people select a pool of external specialists (for biology and medicine, this is approximately 300 people) without any intervention from RFBR staff. Currently, the foundation is ready to include members of the Russian scientific community in an assessment of project applications. A key role in the expert assessment is played by the section head. This individual forwards applications to specific experts. Each application is analyzed by two or three specialists, who then rate the project on a nine-point scale. After all the reviews have been received, the projects are discussed at a meeting of the expert committee. Sometimes this meeting can decide to grant a project with a lower score in place of a bid with a higher score. "Publications in peer-reviewed journals with high impact factors (which, sadly, are mostly foreign journals) make the scoring much easier," adds Smirnov. However, there are no formal bibliometric requirements. The expert assessment is a lengthy process: decisions on applications which have been received 
up until September 15 are announced in early March. The reviews are not disclosed to the applicants. The RFBR admits this is a serious drawback; however, the staff workload and problems with the contents of the reviews do not permit this to be rectified at this time. For instance, an expert can write that the work is interesting, the group professional, etc., but still score the project only 5 points. A system for sending reviews back to the applicants is in the works, but as of now there are no specific dates. A somewhat separate aspect of RFBR activity is the applied research support program, which finances studies aimed at practically implementing their results. Agreements with various government academies and institutions are the basis for a competition of implementation-oriented projects (code "ofi-c"). This program is aimed at helping leading scientific groups develop their promising results. The first interdisciplinary competition of implementation-oriented projects was conducted in 2009 ("ofi-m"). According to the head of the Oriented Research Department of RFBR Sergey Tsiganov, biological and medical applications in 3 of the 18 RFBR-approved fields of research received funding: "A Scientific Basis for the Creation of New Drugs and Vaccines," "Fundamental Aspects of the Genomics and Proteomics of Eukaryota" and "Cognitive Studies." The largest number of projects (28) involves the creation of new drugs. The average funding of an implementation-oriented grant is approximately 1.6 million rubles per year. All the bids for the "ofim" and "ofi-c" competition are assessed by an expert committee. Only those groups that have previously received RFBR or other well-respected grants and/or those that have publications in high-rated journals are allowed to bid for this type of grant. In all other aspects, the conditions are the same as in the initiative project competition. The foundation also has a small program for the targeted funding of projects which receive interest from the Russian Academy of Medical Sciences (RAMS).

\section{FUTURE AND PROSPECTS}

Almost every active scientist in Russia agrees that RFBR is the most effective mechanism of competition-based funding in a wide range of basic research fields. Notable factors are the high quality of expert assessment, clear rules for applicants, and limited amount of bureaucracy. The main problem is the size of the grants, which is not on par with the current needs of experi- mental science. In these circumstances, the government initially approved the doubling of the foundation's budget in 2010 but later cancelled these plans, thus not just stopping RFBR growth, but setting it back. The 2009 budget of the foundation was 7.1 billion rubles, while in 2010 the foundation received only 6 instead of the pre-crisis planned 12 billion. There is no way the foundation can grow under such extreme external sequestering. Currently, the foundation can only reminisce about the planned increase of the average grant to 1 million rubles, the creation of start-up grants for young researchers and the joint funding of offers for implementation-oriented projects from abroad, etc.

The remaining hopes of RFBR staff are on the innovational plans of the Presidential Modernization Committee. The concept of an "innovation elevator" was presented on one of the meetings of the committee, and this involved some of the studies supported by the foundation. The RFBR itself was named an "institute of development." Possibly these words will be followed by decisions that can help resuscitate this development. The chances that the government will unexpectedly realize the importance of basic research per se are much slimmer.

\section{Nevertheless, despite the external limitation of the development of the Russian grant system, we have asked leading Russian biologists to share their ideas on the activity of the RFBR by answering the following three questions:}

1. What can be done with the funding for an RFBR grant, what does it help achieve?

2. What are the pros and cons of the foundation's activity, apart from the amount of granted funds?

3. What steps should be taken to improve the support of biological projects by the RFBR?

Elizaveta Bonch-Osmolovskaya, Doctor of Biological Sciences and Head of the Hypertermophilic Bacterial Communities Laboratory of the Vinogradsky Institute of Microbiology, Russian Academy of Sciences (RAS)

\section{“RFBR GRANTS ARE VERY WELL SUITED FOR STARTING A NEW GROUP OR LABORATORY."}

1. RFBR grants really are pretty small. But they can support the work of a small group. They are very well suited for when a group or laboratory is just starting to take off. This was the case for our laboratory; for several years the RFBR funding was the only thing we had, and then we managed to move on to larger projects. Our laboratory has grown so much that RFBR funding is not enough, but we still apply for these grants and receive funding for small-scale pilot projects which may yield data useable for larger projects.

2 . One advantage is the fairness of the granting system (compared with most other competitions and programs). Of course some people will surely receive funding even if they have a bad project, but in the RFBR this does not prevent researchers that really do work at a modern level from receiving support. A definite disadvantage is the absence of feedback; people should be informed on why their project was rejected, which means seeing the reviews.

3. My opinion is that regional competitions (in Russia) should be abolished, since the level of the research there is 
RFBR: Opinions of Expert Science Theorists

Tatiana Kuznetsova, PhD in Economical Sciences, Director of the Scientific, Technical, Innovational, and Informational Policy Center for the Institute of Statistics and Economics of Knowledge at the State University of the Higher School of Economics.

\section{"SMALL GRANTS SUPPORT SCIENTISTS, NOT SCIENCE."}

Developed countries have arrived at an effective system of scientific funds, which usually have a special legal status. Since these funds are widely acknowledged as institutes of development, they are constantly experiencing various complex changes, widening of activities, direction of efforts (reorientation for multiprofile research, diversification of theme research, support of innovation projects, facilitating the transfer of scientific results, investments into small science-intensive companies, support of cooperation, increasing information, and expert functions).

What we see in Russia is quite different. Generally speaking, scientific funds in Russia have problems which can be separated into four aspects connected with scope, variety, time limitations, and regulations on their founding and activities.

(1) Since the funds allocated from the government are small, the average size of a grant is also moderate. This makes these grants less attractive and prevents increased efficiency: small grants mostly support the scientists, not the science.

(2) The conditions, mechanisms, and allocation and distribution of funding for the unreciprocated support of projects, including grant support, still remain unclear. Since the funds are participants in the budget process, they must obey budget law. The conflict between their status as head distributers of budget funds and their nondepartmental granting of funds still remains unresolved. The government does not fully understand the specifics of the activities of such foundations, which is competition-based funding of initiative projects selected on the basis of qualified expert assessment. Many issues on the selection of projects, forms for financing contracts of competition winners, etc., remain unresolved.

(3) The issue of which type of legal entity must be used for scientific foundations still remains unclear. The project for changing the legal status of some institutions which is currently being drafted will seemingly only worsen the situation.

4) RFBR and the Russian Humanitarian Scientific Foundation (RHSF) are aimed at financing basic research and are limited in their ability to support other types of projects, sometimes in conjunction with allegations of embezzling the budget funds.

There are still no special normative regulations for the activity of the foundation, which creates a number of problems (the legal status of the organization, the legal status of the allocated funds, and the conditions and procedures for their distribution).

The legal status of the grant itself is also an issue (the conditions of the granting agreement; right to grant funds to both individuals and legal entities). It is important to widen the rights of the foundations to use various financial schemes (government contracts, granting agreements, loan agreements, etc.). It is also worthwhile to allow foundations to receive funding not only from the federal budget, but also from other sources.

The problem of Russian scientific foundations is not only in the fact that the legal basis for their activity is being incorporated into the existing laws at such a slow rate. This problem is being solved and will be circumvented at some point. The main issue is the understanding and development of the ideology of research and innovation support via a system of various foundations and the development of these foundation's missions.

Currently, the capabilities and authority of the existing foundations and their role in the support of science and innovations are being diminished in a regular and methodic manner, which obviously conflicts with the current trend around the world.

\section{Irina Dezhina, Doctor of Economic Sciences and Section Head at} the Institute of World Economy and International Relations

\section{"FOUNDATIONS NOT ONLY SUPPORT SCIENCE, THEY ALSO SUPPORT THE WHOLE RESEARCH PROCESS."}

Governmental scientific foundations (RFBR and RHSF) are "by default" considered the most transparent and fair mechanisms for the distribution of budget funding for scientific research. Their funds are allocated not only for basic research, but also for processes which are needed for productive research: RFBR has efficiently financed and administered a program for the support of leading scientific schools and developed systems for buying and (most importantly) using scientific equipment for the benefit of all the grantees. This includes support in the creation of noncommercial collective-use centers.

RFBR and RHSF are very popular among scientists since they are just about the only institutions which can grant funds for participation in conferences, including those that take place abroad. Scientific organizations and universities rarely have the funds to pay for the science-related travel of employees that do not occupy high administrative positions.

Nevertheless, scientific foundations continue to be affected by the not-so-friendly policy of the government. First of all, these foundations are underfinanced on a regular basis. The law stipulates that RFBR and RHSF should receive $7 \%$ of the budget funds allocated for civilian science. According to information from Rosstat (Russian Statistic Agency), in 2007 only $6.1 \%$ of the funds were allocated through grants (this includes the Foundation for the Support of Developing Small Enterprises in Scientific and Technical Fields, which should receive $1.5 \%$ according to Russian Law), in 2008 it was 6.7\%, and in 2009 (preliminary data) it was $5.6 \%$.

Secondly, scientific foundations have a very unstable legal status. This issue was supposed to be resolved in 2009. Ideally the status should be such that the foundations could grant funding to any grantee that wins the competition. This is the way in which they currently function, but this was legal only due to a delay stipulated in the Budget Code and which was in effect only up to January 1, 2010. In December 2009, the existing order of the financial support of grants was prolonged; in other words, a decision on the foundations was just delayed for another year. The optimal solution would be to amend the budget code so that the foundations would have a special status which would allow them to be the head distributors of the budget funding and distribute these funds in the form of grants. Obviously, the budget of the foundations should be increased and the administration of some programs should be transferred (returned) to the foundations. In the absence of other effective mechanisms, the foundations can also become a major organizational center for the expert assessment of scientific projects (which can even involve international specialists). 
much lower than in the main competition for initiative projects. It might be prudent to temporarily suspend other types of RFBR competitions (publishing, participation and organizing of conferences and expeditions) in order to increase the grants for initiative projects. It is important to understand that, if there is no real scientific research, everything else will be irrelevant. Personnaly, I would close the implementationoriented basic research programs. The Ministry of Science can handle this issue (The author is referring to the Federal Targeted Program "Research and Development in Priority Directions." This program has been suspended in 2010 - I.S.).

Vladimir Gvozdev, RAS member and Head of the Molecular Genetics of the Cell Section of the Institute of Molecular Genetics, $R A S$.

\section{"A RESEARCHER WITH PUBLICATIONS IN DECENT JOURNALS WILL ALMOST CERTAINLY RECEIVE A GRANT."}

(1) You can buy some reagents. Add a little to a very meager salary. The size of the grant certainly does not allow you to buy any serious equipment.

(2) A researcher with publications in decent journals will almost certainly receive a grant. The forms for the grant application are acceptable and are not as intimidating as those you can see in the lots in the Ministry of Education and Science and RosNauka. The forms could be further simplified by excluding the addresses and phone numbers of the grant participants.

It is a pity that the RFBR no longer supports scientific schools. Applying for the funding of a scientific school is now a most excruciating affair, and officials which do not seem to have any other work to do demonstrate their "active participation" by thinking up newer and newer forms and requiring extremely long reports. My opinion is that the expert assessment in the RFBR is well-qualified.

(3) The foundation needs money, which is used up by other programs that lack qualified expert assessment or which promote false "innovations."

Alexey Bogdanov, $R A S$ Member and Deputy Director of the Belozersky Scientific Research Institute of Physico-
Chemical Biology at Moscow State University.

\section{“THE RFBR HAS CHANGED THE FACE OF RUSSIAN SCIENCE."}

(1) The average RFBR grant can support the work of one post-graduate student (which includes a moderate addition to his or her meager scholarship) and buy some reagents and materials. However, it is important to bear in mind that large laboratories which have several groups with independent lines of research usually receive more than one grant. RFBR has always approved of this practice; this strongly differs from the policy of RosNauka, which states "one application for one lot" for each organization, irrespective of its size. This allows individual grantees in a laboratory to pool their resources for a common task.

Moreover, almost all the organizations to which the grantees are affiliated require the allocation of $15-20 \%$ of the grant for the support of the infrastructure (for instance, the support of a computer server) of the institute or department. This is also beneficial for the researchers. Another important factor is the moral support a researcher receives together with an $\mathrm{RFBR}$ grant. His project has been approved by a serious and qualified expert committee and his reputation with his superiors has obviously increased.

(2) Complimenting the RFBR is not very appropriate on my part, since I have been lucky enough to work for the foundation since its beginning. Nevertheless, based on my experience in many other expert committees, both Russian and international, I can confidently say that there is nothing better or more beneficial for Russian science than the RFBR. The main thing about the RFBR is the high professionalism of the people who are involved in workings of the foundation (beginning with expert reviewers and ending with the foundation's staff). The Russian scientific community has been schooled by the RFBR. It has been learning to write grants, to realistically judge the perspectives and results of their work, and to value international publication. The RFBR has changed the face of Russian science.

(3) My opinion is that the RFBR could improve the mechanisms of sup- port for young scientists. Currently the foundation helps young researchers participate in international conferences (where else can such funding be obtained?) and facilitates the organization of young scientists' conferences. However, the so-called "Mobility for Young Scientists" program which supports trainee programs in various organizations inside the country is not working to its full capacity. The financing of the program is adequate. In my opinion, these funds would be better suited for supporting the first independent grants of young researchers (when a grant is allocated as an advance payment for a good idea).

Olga Lavrik, Corresponding Member of $R A S$ and Head of the Bioorganic Chemistry of Enzymes Laboratory of the Institute of Chemical Biology and Basic Medicine, $R A S$.

\section{“THE REVIEWING PROCEDURES IN THE RFBR ARE ON PAR WITH INTERNATIONAL STANDARDS."}

(1) The size of RFBR grants is indeed small, and it has become even worse since the funding of grants in 2010 has been reduced instead of being increased, as would have been appropriate, because the role of RFBR in the development of basic research in Russia and in developing scientific personnel is hard to overestimate. The RFBR is practically the only scientific research foundation which has a serious and qualified expert assessment procedure for projects and which also makes annual reviews of the project reports. If the work is conducted in an unsatisfactory manner, the funding is stopped prematurely. There are, of course, other programs (such as the RAS "Molecular and Cell Biology" program) which are equally serious about objective ratings and judging the quality of publications, but the RFBR is still very important.

We mustn't forget that the RFBR has existed and functioned for many years; it has accomplished an enormous amount of work and has established a good set of principles for the selection of the best projects. This is great experience which should be used for the further development of basic research. Indeed, it would be criminal to negate all these results. 
Another important aspect of RFBR grants is the fact that funding can be obtained not only by the head of a laboratory, but also by other leading personnel such as independent researchers and even young scientists. This is a very important issue; RFBR grants support pilot projects, which are the essence of basic research.

(2) As was mentioned previously, the foundation has a notable system of grant review and the application and reporting procedures are relatively simple. Everything is easier to judge in comparison. There was a time when we thought the RFBR system was overly complicated. But now, when we see the horrible bureaucracy involved in applications for research support by RosNauka and their reporting procedures, the RFBR procedure seems relatively easy and simple.

My opinion is that the largest part of RFBR resources should be focused on the funding of basic initiative grants, in which case they could become much larger. The creation of several new programs and competitions in the RFBR, including a scientific collaboration with South Ossetia does not seem justifiable to me. Moreover, the financing of oriented projects is in a certain sense repeating the work of RosNauka. As is evident from its name, the foundation should consider basic research a priority.

(3) The funding of initiative projects should obviously be increased; an average grant should be close to 1 million rubles. The current system for reviewing projects should be conserved and developed. It is objective and on par with international standards.

Konstantin Severinov, Doctor of Biological Sciences; Professor at Rutgers University (United States); Head of the Molecular Genetics of Microorganisms Laboratory in the Gene Biology Institute, $R A S$; Head of Regulation at Prokaryote Mobile Element Gene Expression group at the Institute of Molecular Genetics, $R A S$.

\section{"RFBR IS A RAY OF HOPE IN OUR SCIENTIFIC REALITY."}

(1) I was very interested to know the average size of a grant (380 000 rubles). My RFBR grant is smaller than average. Since the sum I applied for was much larger than the mentioned average, I cannot but wonder about the reasons for such a sad fact. I do not know the real answer, but I consider the following possibilities:

(I) all the applications are reduced by a certain (very large) percent,

and I modestly asked for a lower sum than my colleagues;

(II) other researchers applied with better projects that deserved more funding (since we are talking about the average size of a grant, this means that the research in my group is conducted below the average level in Russia, or more correctly, the average level funded by the RFBR);

(III) the decision on the grant's exact size is not based on the quality of the project or the funding required by the researcher, but on some other factors (for instance "rich American guys" receive less money in order to keep up the social justice).

The main role of an RFBR grant is to pay additional salaries to postgraduate students (one or maybe two). The fact is that RFBR funds are considered nonbudgetary funding, and budgetary funding (such as the RAS programs) cannot be used to pay postgraduate students. This cannot be understood rationally; you just have to keep it in mind and accept it. These additional salaries take up about half of the grant. The rest is used to buy plastic tubes, pipette tips, etc. These are small things, but a laboratory cannot work without them. If there is a need, one can pay for a single business trip with the grant money. You cannot buy any equipment for these sums of course. Finally, 15\% of the grant is overhead for the institute.

Generally, an RFBR grant is better to have than not, but it does not allow you to conduct full-scale research on the projects stated in the applications; additional funds are a necessity. If I have four articles in international journals after 3 years of RFBR support, all of which cite the grant as a source of funding, this is to be taken with a grain of salt. Yes, the grant's funding was a contributor in this result, but these results could be obtained without this grant. If this grant was the only source of funds, the work would not have been completed. I was also granted a larger RFBR grant (ofi-c). I obviously like it better in proportion to its larger size, as compared to my initiative grant. More funds give more possibilities. We even bought a microbiological shaker costing $\$ 10000$.

(2) The foundation has a wonderful website (the "Grant-Express" system started working before a similar system was implemented in the NIH in the United States, and the system works very well). The forms are fairly adequate in general, you don't get the feeling that people are trying to torture you with them. Well, maybe just a little, for instance when the reports need to include lists of references from articles supported by the grant.

I also cannot understand why the foundation needs the tax address information for the researchers involved, since the turnover of the participants is high. This means the grantee has to run around after people, asking for their ITN (Individual Taxpayer Number) and home address. It is obviously a disgrace that the applicants do not see the reviews for their projects.

The RFBR has a very good and needed system of support for trips to conferences; several researchers from my lab have used this option. It did involve several idiosyncratic requirements, and the staff of the foundation was not always polite when asked for information, but as they say, you gotta do what you gotta do.

The foundation has a series of joint competitions with various countries, starting with Kyrgyzstan and ending with the United States. I think this is not the best part of the foundation's activities, it is very much nontransparent. When I discussed the options with the program administrators on the American side, I received direct advice not to apply. I think all these programs should be discontinued and the funds should be allocated for increasing the average size of the grants, without decreasing the number of grants.

What I consider an utter anachronism is the requirement of a hard-copy version of the application. I need to take it all across Moscow, and others need to mail it across the whole of Russia just to drop it into the "letters and newspapers" box. What is the need for all this paperwork when the foundation has a wonderful website?

(3) What about further development? Introduce the practice of sending the 
application reviews to the applicants, publish the lists of expert reviewers, introduce the rotation for these experts (this mechanism is in place only for members of the expert councils, but not for external experts - I.S.) and also publish the criteria which are used during the selection of these experts. These criteria are to be followed with all due accuracy and reason. Grants need to be increased, but without decreasing their number. All the attempts to select "priority lines of research" and introduce "targeted funding" are susceptible to abuse and are usually initiated by people whose ability to select priorities is very questionable.

In general, the RFBR is a ray of hope in our scientific reality. It needs some small improvements, but the main principles of its activity are sound.

Piotr Chumakov, Doctor of Biological Sciences, Head of the Cell Proliferation Laboratory of the Engelhardt Institute of Molecular Biology, RAS.

\section{“RFBR IS THE ONLY HOPE SOME SCIENTISTS HAVE OF GETTING FINANCIAL SUPPORT."}

The sad condition of Russian science is in part due to the ridiculous amounts of financing. The RFBR is not the only source of funding for basic researchers, but it is the most important one. For most scientists who are not a part of a powerful interest group but just doing science, the RFBR is the only chance of obtaining support. Of course, since the average size of a grant is 380000 rubles, no serious projects can be initiated. This amount is 10 times less than is needed in order to support an experimental physico-chemical project. That is, if the appropriate equipment is already in place.

Basic research is valuable only if it yields new data. The price of obtaining new data is dependent on objective factors, such as the prices for reagents and other consumables. Throughout the world, researchers use common standard sources for most laboratory materials. Unfortunately, most of these materials are manufactured abroad and something that costs $\$ 1$ in Western countries can cost $\$ 1.5-2$ in Russia after all the custom duties and commissions. This means that the cost of scientific results in Russia is much higher. In the
United States it is considered normal for an active researcher to use up to $\$ 15$ 000-20 000 worth of materials annually in the course of successful work. This figure does not include salary or equipment.

Which means that a Russian researcher must use \$25000-39000 just to stay on par. Therefore, a $380000 \mathrm{ru}-$ ble grant can only be used to prolong the agony of science. Nevertheless, Russian scientists still exist and even yield results with these meager sums. However, the efficiency of this process is incomparable to the real potential these scientists have. Only the hope of a better tomorrow keeps these people going.

When a difficult financial situation occurs, there is hope that it will be circumvented and everything will be back on track. But when this insanity is still going on after 20 years, when it is getting worse and the growth of systems for supporting basic research and open competitions is being negated, a pressing question comes to mind: What have we been waiting for all these years? The constant calls for "modernization" and "innovation" sound especially funny in this situation. Where will these things come from when the tree is being chopped off at the roots?! What kind of innovations can come from dead science? Or did somebody invent a new, "innovative" method of getting innovations out of thin air?

2-3. Pros:

(I) Applications for funding are sent in by researchers, without any go-aheads from their superiors. This system lets a researcher feel like a real Russian Scientist who is venturing into the Secrets of Existence;

(II) The applications are assessed by scientists and not by officials. The main criterion for the grant is the scientific value of the proposed project;

(III) The fact that a researcher has an RFBR grant gives him or her some protection against abuse from officials or institute administrators, who do not always work in the interests of scientific development;

(IV) Each researcher can decide what he or she will do with the grant money; nobody asks why the money was used in such and such a way. This system is good, because the researcher feels trust, while the institute's accounting system is still there to safeguard against misuse of funds.

(V) The foundation sets a limit for the funds that can be used by the institute without consent from the grantee. This gives the researcher an additional degree of protection against local administrator abuse;

(VI) Applications and reports are sent in via the internet using unified application forms. The applications are relatively short, which is adequate, considering the moderate size of the grant. If the funding were to be increased, the small amount of paperwork would be a drawback because a more strict review would be in order.

\section{Cons:}

(I) The procedure for decisions on whether to support or decline a project is somewhat nontransparent. What is missing is feedback on the results of the project's review, which should be available to the researcher. Publishing a list of projects and the grant sums for ongoing and completed projects would also be good, as well as a list of the members of the themed expert committee who take part in the meeting where the review results are discussed;

(II) the scientific community is a very tight-knit group, which creates a basis for conflicts of interest and personal conflicts to affect the course of science. The existing expert assessment procedure still has room for manipulation and subjective decisions. A correct move would be to involve both Russian experts and specialists from abroad, taking into account that a large portion of Russian speaking scientists are working in other countries. This potential should be used, and their involvement in Russian matters should be stimulated;

(III) the funding is allocated with delays, and scientists are left without any money in the first months of the year. Our inflexible financial system does not allow the creation of legal "stashes" for such times, pushing us towards unavoidable (if the work is to be continued) violations;

(IV) it would be good to have two or three types of grants which would differ in their timeframe and amount of funding. For instance, many initiative projects are not concluded in three years. Five-year grants are also necessary. 